\title{
Supercritical Phase Equilibria Modeling of Glyceride Mixtures and Carbon Dioxide Using the Group Contribution EoS
}

\author{
Tiziana Fornari, Daniel Tenllado, Carlos Torres, and Guillermo Reglero \\ Department of Production and Characterization of Novel Foods, Instituto de Investigación en Ciencias de \\ la Alimentación CIAL (CSIC-UAM), C/Nicolás Cabrera, 9. Campus de Cantoblanco, 28049 Madrid, Spain \\ Correspondence should be addressed to Tiziana Fornari, tiziana.fornari@uam.es
}

Received 19 May 2011; Revised 27 July 2011; Accepted 29 July 2011

Academic Editor: Roumiana P. Stateva

Copyright ( 92011 Tiziana Fornari et al. This is an open access article distributed under the Creative Commons Attribution License, which permits unrestricted use, distribution, and reproduction in any medium, provided the original work is properly cited.

\begin{abstract}
The Group Contribution Equation of State (GC-EoS) was extended to represent high-pressure phase equilibria behavior of mixtures containing mono-, di-, triglycerides, and carbon dioxide $\left(\mathrm{CO}_{2}\right)$. For this purpose, the alcohol-ester and the alcoholtriglyceride binary group interaction parameters were regressed in this work, using experimental phase equilibria data from the literature. The capability of the parameters obtained was assessed by applying the GC-EoS model to simulate the supercritical $\mathrm{CO}_{2}$ fractionation of a complex glyceride mixture, which was produced by the ethanolysis of sunflower oil. Experimental data was obtained in a countercurrent packed extraction column at pressures ranging from 16 to $25 \mathrm{MPa}$ and temperatures from 313 to $368 \mathrm{~K}$. The GC-EoS model was applied in a completely predictive manner to simulate the phase equilibria behavior of the multistage separation process. The chemical analysis of the glyceride mixture allowed a significant simplification of its complex composition and thus, a simple and satisfactory simulation of the supercritical extraction process was achieved.
\end{abstract}

\section{Introduction}

Lipid compounds are gaining increasing attention due to a wide range of applications in the food industry. Particularly, monoglycerides and diglycerides are potentially attractive starting materials for numerous synthetic applications $[1,2]$. They can be employed for the synthesis of structured lipids, phospholipids, glycolipids, lipoproteins, and preparation of numerous enzyme agonists and antagonists [3]. Monoglycerides are the most commonly used surface-active lipids and can be used for emulsification, aeration, as defoaming agents, oil stabilizers, and so forth [4]. Additionally, diglycerides have been developed in recent years as alternatives for fat/oil [5].

Mono-, di-, and triglyceride mixtures are commonly produced by glycerol esterification with fatty acids, transesterification of triglycerides or lipase-catalyzed hydrolysis, or alcoholysis of oils. Generally, the goal is the manufacture of a final product with a defined glyceride composition, and purification of the reaction product is often necessary.
Supercritical carbon dioxide $\mathrm{SCCO}_{2}$ has been widely studied as a potential solvent for lipid extraction and fractionation [6]. In the case of glyceride mixtures, differences in molecular weight, polarity, and chemical structure of the glyceride species directly affect the resultant $\mathrm{SCCO}_{2}$ separation process. That is, the distribution of the different species between the liquid and supercritical phase depends not only on the $\mathrm{CO}_{2}$-glyceride and glyceride-glyceride interactions, but also on the glyceride vapor pressures [7].

Solubility data of mono-, di-, and triglycerides in $\mathrm{SCCO}_{2}$ reported in the literature [8-12] corroborate these ideas. Although trilaurin has a molecular weight 2.3 times higher and a vapor pressure 150 times smaller than monolaurin, the high polarity of monolaurin was found to limit its solubility in $\mathrm{SCCO}_{2}[10,11]$. When the fatty-acid chain length is increased, a greater monoglyceride solubility is obtained compared to the triglyceride solubility of an equivalent fatty-acid chain length, as demonstrated for the case of the monoolein/ triolein pair [12]. Therefore, as the fatty-acid chain length increases, the difference in molecular weight and vapor 
pressure between the mono-, di-, and triglyceride becomes more significant, minimizing the polarity differences of the respective lipid species.

Solubility and vapor-liquid equilibrium data are frequently employed to the regression of phase equilibria thermodynamic model parameters. Then, these models can be utilized to the simulation and optimization of supercritical extraction (SFE) processes. Particularly, the Group Contribution Equation of State (GC-EoS) $[13,14]$ has been applied as the phase equilibria predictive tool in the simulation and optimization of supercritical countercurrent extraction and fractionation of several lipid-type raw materials [15-18]. The great advantage of the group contribution approach is the representation of the usually complex (multicomponent) raw material by using a reduced number of functional groups. In turn, the validity of the group contribution method is very much supported by the accuracy of the resulted group interaction parameters.

Recently, Fornari [19] presented a revision of the GCEoS parameter table and demonstrate the capability of the model to represent high-pressure vapor-liquid equilibria of several oil-constituent substances (fatty acids, fatty acid alkyl esters, triglycerides, tocopherols, and squalene) with $\mathrm{SCCO}_{2}$. Nevertheless, the lack of some binary group interaction parameters in the GC-EoS parameter matrix did not allow the phase equilibria prediction of glyceride mixtures and $\mathrm{CO}_{2}$. Thus, the alcohol-ester and alcohol-triglyceride binary interaction parameters were obtained in this work, and the parameters regressed were tested by applying the model in a predictive manner to simulate the supercritical fractionation of a complex glyceride mixture.

\section{Experimental}

2.1. Equipment and Method. The supercritical fluid extraction (SFE) plant employed in this work comprises a countercurrent extraction column (316 stainless steel), two cascade separator cells $(270 \mathrm{~mL}$ capacity), and a cryogenic trap at atmospheric pressure. The column is $100 \mathrm{~cm}$ height, $12 \mathrm{~mm}$ internal diameter and is packed with Fenske rings $(3 \times 0.5 \mathrm{~mm})$. The extract can be fractionated by a cascade decompression in the two separator cells. All units are electrically thermostatized. The SFE pilot plant has computerized instrumentation and a control system with several safety devices including valves and alarms [16].

A continuous flow of $\mathrm{CO}_{2}$ was pumped (Dosapro Milton Roy pump) up to the extraction pressure and preheated up to the extraction temperature before being introduced into the packed column. When the operating pressure and temperature were stabilized, the liquid sample was pumped $(100 \mathrm{~mL} / \mathrm{h})$ from the top of the extraction column during $60 \mathrm{~min}$. Then, $\mathrm{CO}_{2}$ was introduced into the column for additional $30 \mathrm{~min}$ (without pumping liquid sample) to ensure that all material was extracted. The liquid sample was also preheated up to the extraction temperature before being introduced into the column and thus, the extraction procedure was carried out under isothermal condition. In all experiments, the first separator (S1) was maintained at $15 \mathrm{MPa}$ and $333 \mathrm{~K}$, while the second separator cell (S2) was maintained at low pressure $(<2 \mathrm{MPa})$ in order to recover all the remained extracted material in this unit. Samples were collected from the fraction not extracted or residue (bottom product) and from the liquid material precipitated in the separators (top products). All samples were weighted and analyzed; the material balance closed in all experiments with an accuracy of $90 \%$ or greater. The compositions of raffinate (bottom product) were employed to test the GC-EoS model simulation.

\subsection{Materials and Analysis}

2.2.1. Sample and Reagents. Sunflower oil was purchased in a Spanish market. The partial ethanolysis of the oil was carried out in our laboratory as described in previous work [20]. According to the analysis carried out in our laboratory, the reaction product resulted contained (weight basis) $48.2 \%$ of fatty acid ethyl esters, $17.0 \%$ of monoglycerides, $26.5 \%$ diglycerides, and $7.9 \%$ triglycerides, together with minor amounts of free fatty acids. Carbon dioxide N38 (99.98\%) was purchased to AL Air Liquide España S. A. (Madrid, Spain). All solvents used were HPLC grade from Lab-Scan (Dublin, Ireland).

2.2.2. HPLC Analysis. The composition analyses of the neutral lipids were effected on a kromasil silica 60 column (250 $\mathrm{mm}$ by $4.6 \mathrm{~mm}$, Análisis Vinicos, Tomelloso, Spain) coupled to a CTO 10A VP 2 oven, an LC-10AD VP pump, a gradient module FCV-10AL VP, a DGU-14A degasser, and an evaporative light scattering detector ELSD-LT from Shimadzu (IZASA, Spain). The ELSD conditions were 2.2 bars, $35^{\circ} \mathrm{C}$, and gain 3 . The flow rate was $2 \mathrm{~mL} / \mathrm{min}$. A splitter valve was used after the column and only $50 \%$ of the mobile phase was directed through the detector. The column temperature was maintained at $35^{\circ} \mathrm{C}$. The mobile phase utilized has been previously reported by Torres et al. [21].

2.2.3. Gas Chromatography. For the analysis of fatty acid ethyl esters, one $\mu \mathrm{L}$ of the diluted sample was injected into an Agilent (Avondale, PA) gas chromatograph (6890N Network GC System) coupled to an autosampler (Agilent 7683B). The capillary column was a $30 \mathrm{~m} \mathrm{HP}-88$ (Avondale, PA) $(0.25 \mathrm{~mm}$ i.d.). The temperatures of the injector and detector were 220 and $250^{\circ} \mathrm{C}$, respectively. The temperature program was as follows: starting at $100^{\circ} \mathrm{C}$ and then heating to $180^{\circ} \mathrm{C}$ at $20^{\circ} \mathrm{C} / \mathrm{min}$; followed by heating from 180 to $220^{\circ} \mathrm{C}$ at $15^{\circ} \mathrm{C} / \mathrm{min}$. The final temperature $\left(220^{\circ} \mathrm{C}\right)$ was held for 30 minutes. Hexane was employed as solvent in preparing the samples. Identification of the various free fatty acids was based on a PUFA no. 3 standard (no. 4-7085) obtained from Supelco.

\section{The GC-EoS Model}

The GC-EoS $[13,14]$ is a group contribution equation of state originally developed for both nonpolar and polar components. The residual Helmholtz energy of the system is calculated assuming two contributions: a free volume repulsive term and a contribution which accounts for energy 
attractions among groups. A detail description of the model equations is given in the appendix.

In the repulsive term, each substance is characterized by its critical hard sphere diameter $d_{c}$. In the original model [13], the $d_{c}$ values are calculated from critical properties for gases, and for solvents are fitted to pure component vapor pressure data. Nevertheless, these procedures cannot be adopted for low-volatile and thermolabile substances, such as high molecular weight glycerides, since their critical parameters are unattainable and the vapor pressure data are usually scarce and inaccurate. In these cases, the following procedure, which was applied in this work, can be adopted. First, Fedors group contribution method [22] is used to calculate the glyceride critical temperature, and the procedure described by Bottini et al. [23] (based on the use of infinite dilution activity coefficient data) to estimate the glyceride $d_{c}$ values. Then, the glyceride critical pressure can be derived from (A.5) of the appendix.

The GC-EoS attractive term has five pure-group parameters $\left(T^{*}, q, g^{*}, g^{\prime}\right.$, and $g^{\prime \prime}$ and four binary interaction parameters $\left(k_{i j}^{*}, k_{i j}^{\prime}, \alpha_{i j}\right.$, and $\left.\alpha_{j i}\right)$. All pure group and binary group interaction parameters required to the phase equilibria modeling of glyceride mixtures and $\mathrm{CO}_{2}$ are available in the literature [19] except for the alcohol-ester and alcoholtriglyceride interaction parameters. These parameters were adjusted in this work using phase equilibria data from the literature. The alcohol-ester interaction was regressed using a large set of vapor-liquid equilibrium (VLE) data corresponding to binary 1-alcohol + ester mixtures [2429], and the alcohol-triglyceride interaction parameters were adjusted using infinite dilution activity coefficient $\left(\gamma^{\infty}\right)$ data of 1-alcohols and 2-alcohols in triglycerides [30-32].

\section{Results and Discussion}

4.1. Regression of the Alcohol-Ester Binary Interaction Parameters. Table 1 reports the corresponding literature references of the alcohol + ester VLE data employed in the regression of the alcohol $\left(\mathrm{CH}_{2} \mathrm{OH}\right)-$ ester $\left(\mathrm{CH}_{2} \mathrm{COO}\right.$ and $\left.\mathrm{CH}_{3} \mathrm{COO}\right)$ group interaction parameters. Also given in the table are the experimental temperature and pressure ranges, the number of experimental data points, and the standard deviations obtained in the regression procedure. The objective function was the minimization of the standard deviation of the vapor $\left(y_{i}\right)$ and liquid $\left(x_{i}\right)$ mole fractions; in the case that the alcohol + ester binary mixture exhibits azeotropic behavior, the standard deviation in $x_{i}$ and the average relative error in the calculation of the equilibrium pressure $(P)$ were minimized (see Table 1).

Figure 1 depicts some examples of the quality of the regression obtained; as can be deduced from Figure 1(b), the parameters obtained can satisfactory reproduce azeotropic behavior.

Additionally, it should be noticed that no experimental data corresponding to mixtures containing glycerides were employed in the regression of the alcohol-ester interaction parameters. Thus, the application of these parameters in the phase equilibria modeling of the experimental data obtained in this work is carried out in a predictive mode.
4.2. Regression of the Alcohol-TG Binary Interaction Parameters. Table 2 describe the experimental $\gamma^{\infty}$ data employed to fit the interaction parameters between the alcohol $\left(\mathrm{CH}_{2} \mathrm{OH}, \mathrm{CHOH}\right)$ and the triglyceride (TG: $\left.\left(\mathrm{CH}_{2} \mathrm{COO}\right)_{2} \mathrm{CHCOO}\right)$ functional groups. The standard deviations obtained in the regression procedure are reported in Table 3. Following the procedure described before, the critical parameters and $d_{c}$ value of triglycerides were calculated in this work. The results obtained are given in Table 4 and correspond to the same values reported by Fornari [19].

As referred previously, Bottini et al. [23] employed experimental $\gamma^{\infty}$ data of $\mathrm{n}$-alkanes in triglycerides to estimate the $d_{c}$ parameter for the triglyceride molecules; the presence of three long hydrocarbon chains in triglyceride molecules makes their mixtures with n-alkanes nearly athermal solutions and thus, phase equilibria modeling is mainly determined by the repulsive term. In this way, realistic values of triglyceride $d_{c}$ values were determined as can be deduced from Table 4 by comparison of the values regressed from $\gamma^{\infty}$ data with the values obtained from the scarce vapor pressure data available in the literature.

4.3. Estimation of Mono- and Diglyceride $d_{c}$ Parameter. Following the same procedure adopted in the estimation of triglyceride $d_{c}$ values, the $d_{c}$ pure component parameter of monopalmitin and dipalmitin were determined by fitting $\gamma^{\infty}$ data. Alkanes and alcohols were included in the regression procedure due to the presence of hydroxyl groups in the monoglyceride and diglyceride molecules. The $d_{c}$ values resulted are reported in Table 4, and the standard deviations obtained in the regression are given in Table 3 . As in the case of triglycerides, the monopalmitin $d_{c}$ value obtained from $\gamma^{\infty}$ data is in accordance with the value regressed from a single vapor pressure data (see Table 4). That is, the use of experimental $\gamma^{\infty}$ data to fit pure component parameters of highmolecular weight compounds, usually required in EoS phase equilibria modeling, appears as a valid procedure.

Due to the lack of $\gamma^{\infty}$ data of n-alkanes or alcohols in mono- and diolein, the $d_{c}$ values of these glycerides were adjusted using experimental solubility data (weight fractions) in $\mathrm{SCCO}_{2}$ [1012]; the values resulted are given in Table 4 and the standard deviations $(\operatorname{StD} \%=(100 / N)$. $\left.\sqrt{\sum\left[\left(z_{i}^{\exp }-z_{i}^{\mathrm{cal}}\right) / z_{i}^{\exp }\right]^{2}}\right)$ obtained were, respectively, 7.7 and $7.9 \%$ for monoolein and diolein solubility (see Figure 2 ).

\subsection{Phase Equilibria Simulation of the Countercurrent $\mathrm{SCCO}_{2}$} Fractionation of a Complex Glyceride Mixture. The different extraction conditions, that is, temperature, pressure, and solvent-to-feed $(\mathrm{S} / \mathrm{F})$ ratio, employed in the experimental assays are given in Table 5. Also given in the table are the experimental compositions of monoglycerides (MGs), diglycerides (DGs), and triaglycerides (TGs) obtained in the residue (bottom product of the extraction column). The extract (top product) comprises the two liquid fractions recovered in S1 and S2 separators units. The fatty acid ethyl ester (FAEE) yield in the extract (S1 + S2) was higher than $96 \%$ for all extractions reported in Table 5 . That is, in all experimental assays the FAEE was almost completely removed from 


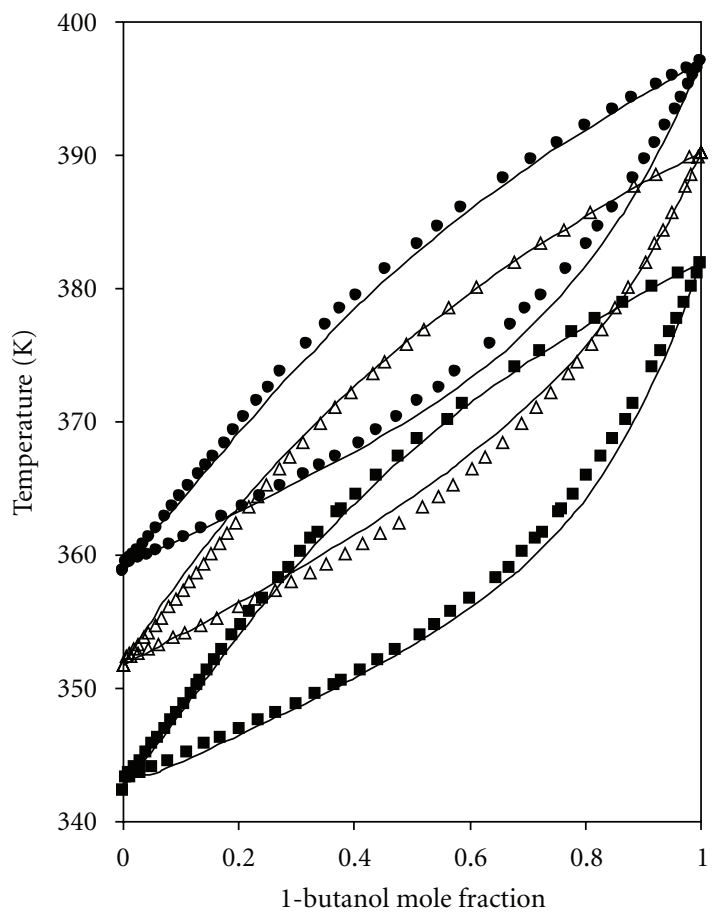

(a)

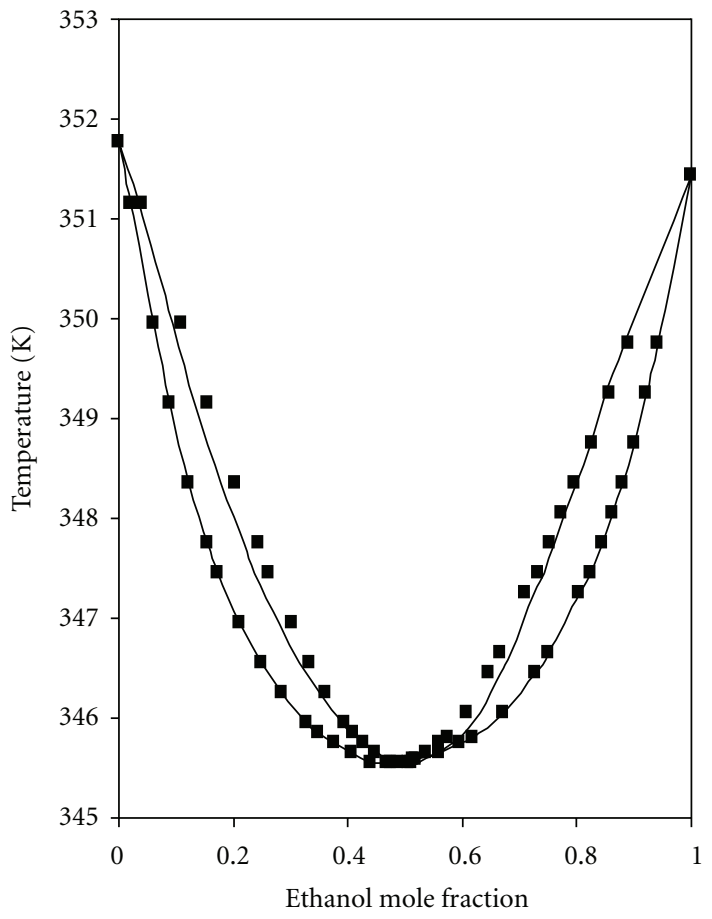

(b)

Figure 1: Comparison between experimental VLE data and the GC-EoS correlation. (a) 1-butanol + methylpropanoate mixtures [25]: 0.74 bar; $(\Delta) 1.01$ bar and $(\bullet) 1.26$ bar. (b) ethanol + methylpropanoate mixtures [27] at 1.01 bar.

TABLE 1: Experimental VLE data and standard deviations obtained in the regression of the alcohol-ester binary group interaction parameters.

\begin{tabular}{|c|c|c|c|c|c|c|c|}
\hline \multirow{2}{*}{ Binary mixture } & \multicolumn{2}{|c|}{ Data range } & \multirow{2}{*}{$N_{\text {exp }}$} & \multirow{2}{*}{$\Delta P \%^{\mathrm{a}}$} & \multirow{2}{*}{$\Delta y \%^{\mathrm{b}}$} & \multirow{2}{*}{$\Delta x \%^{\mathrm{b}}$} & \multirow{2}{*}{ Ref. } \\
\hline & $T(\mathrm{~K})$ & $P$ (bar) & & & & & \\
\hline 1-propanol + methyl propanoate & $328-348$ & $0.2-0.8$ & 45 & & 8.10 & 7.98 & {$[24]$} \\
\hline 1-butanol + methyl propanoate & 348 & $0.2-0.9$ & 20 & & 21.51 & 18.36 & {$[25]$} \\
\hline ethanol + methyl propanoate & $345-352$ & 1.01 & 33 & 3.37 & 6.52 & & {$[26]$} \\
\hline 1-propanol + methyl propanoate & $352-367$ & 1.01 & 37 & 3.64 & 5.00 & & {$[26]$} \\
\hline 1-butanol + methyl propanoate & $342-390$ & $1.3-0.8$ & 118 & & 13.53 & 11.44 & {$[26]$} \\
\hline 1-butanol + ethylacetate & $348-387$ & 0.96 & 20 & & 13.92 & 9.56 & {$[27]$} \\
\hline ethanol + methyl acetate & $330-351$ & 1.01 & 30 & & 9.16 & 11.99 & {$[28]$} \\
\hline 1-propanol + methyl acetate & $330-370$ & 1.01 & 38 & & 10.16 & 9.01 & {$[28]$} \\
\hline ethanol + ethylacetate & $345-350$ & 1.01 & 60 & 13.21 & 12.50 & & [29] \\
\hline
\end{tabular}

${ }^{\mathrm{a}} \Delta P \%=100 \cdot \sum \mathrm{I}\left(P_{i}^{\mathrm{cal}}-P_{i}^{\mathrm{exp}}\right) / P_{i}^{\exp } \mid / N$.

${ }^{\mathrm{b}} \Delta z \%=100 \cdot \sqrt{\sum\left[\left(z_{i}^{\text {exp }}-z_{i}^{\mathrm{cal}}\right) / z_{i}^{\exp }\right]^{2}} / N$.

TABLE 2: Experimental $\gamma^{\infty}$ data employed in the regression of GC-EoS model parameters. TG: triglyceride group, $d_{c}$ : critical hard sphere diameter.

\begin{tabular}{|c|c|c|c|c|c|}
\hline Compounds & $T$ range $(\mathrm{K})$ & $P$ range $(\mathrm{MPa})$ & $N$ & Parameters regressed & Ref. \\
\hline alcohols in triacetin & $314-343$ & 0.1 & 12 & TG-alcohol & {$[30]$} \\
\hline alcohols in tripalmitin & $354-375$ & 0.1 & 15 & TG-alcohol & {$[31]$} \\
\hline alcohols in tristearin, triolein, and trilinolein & $323-363$ & 0.1 & 40 & TG-alcohol & {$[32]$} \\
\hline alkanes and alcohols in monopalmitin & $354-375$ & 0.1 & 21 & $d_{c}$ of monopalmitin & {$[31]$} \\
\hline alkanes and alcohols in dipalmitin & $354-375$ & 0.1 & 21 & $d_{c}$ of dipalmitin & {$[31]$} \\
\hline
\end{tabular}




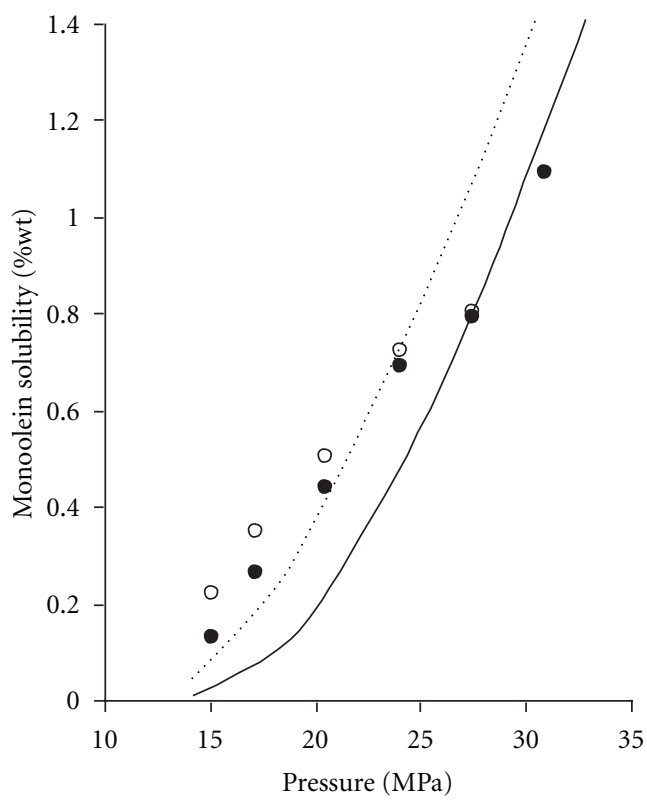

(a)

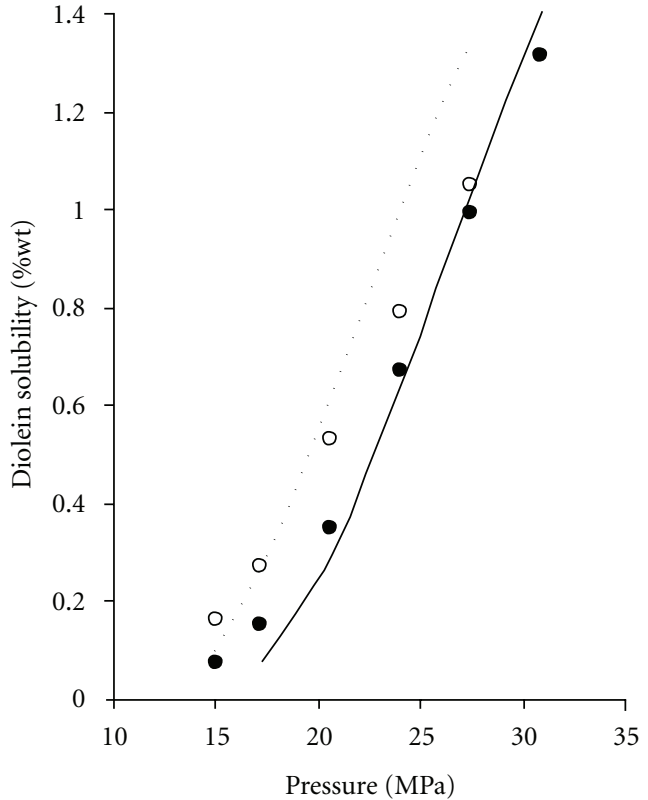

(b)

Figure 2: Solubility of (a) monoolein and (b) diolein in $\mathrm{SCCO}_{2}$. Experimental data [12]: (○) $323 \mathrm{~K}$ and (•) $333 \mathrm{~K}$. GC-EoS calculations: $(\ldots) 323 \mathrm{~K}$ and $(-) 333 \mathrm{~K}$.

TABLE 3: Standard deviations obtained in the regression of GC-EoS model parameters using $\gamma^{\infty}$ data.

\begin{tabular}{|c|c|c|}
\hline $\begin{array}{l}\text { Regression of the alcohol-TG } \\
\text { interaction parameters }\end{array}$ & $N$ & $\Delta \gamma \%$ \\
\hline $\begin{array}{l}\text { ethanol, 1-propanol, } \\
\text { 1-butanol, isopropanol, } \\
\text { isobutanol in tripalmitin }\end{array}$ & 15 & 9.9 \\
\hline $\begin{array}{l}\text { ethanol, 1-propanol, } \\
\text { 1-butanol in tristearin }\end{array}$ & 6 & 7.4 \\
\hline $\begin{array}{l}\text { ethanol, 1-propanol, } \\
\text { 1-butanol in triolein }\end{array}$ & 9 & 7.1 \\
\hline $\begin{array}{l}\text { ethanol, 1-propanol, } \\
\text { 1-butanol, 1-pentanol in } \\
\text { trilinolein }\end{array}$ & 12 & 8.1 \\
\hline $\begin{array}{l}\text { Regression of monopalmitin } \\
\text { and dipalmitin } \mathrm{d}_{\mathrm{c}} \text { values }\end{array}$ & $N$ & $\Delta \gamma \%$ \\
\hline $\begin{array}{l}\text { ethanol, 1-propanol, } \\
\text { 1-butanol, isopropanol, } \\
\text { isobutanol in monopalmitin }\end{array}$ & 15 & 18.5 \\
\hline $\begin{array}{l}\mathrm{n} \text {-hexane, } \mathrm{n} \text {-heptane in } \\
\text { monopalmitin }\end{array}$ & 6 & 11.8 \\
\hline $\begin{array}{l}\text { ethanol, 1-propanol, } \\
\text { 1-butanol, isopropanol, } \\
\text { isobutanol in dipalmitin }\end{array}$ & 15 & 26.1 \\
\hline $\begin{array}{l}\text { n-hexane, n-heptane in } \\
\text { dipalmitin }\end{array}$ & 6 & 11.1 \\
\hline
\end{tabular}

the mixture. Weight fractions of FAEE in the residue were lower than 0.03; residue compositions in Table 5 are reported on a solvent $(\mathrm{CO})$ and FAEE-free basis.
TABLe 4: Pure component parameters of lipid-type substances.

\begin{tabular}{lcccc}
\hline & $T_{c}^{\mathrm{a}}(\mathrm{K})$ & $P_{c}^{\mathrm{b}}(\mathrm{bar})$ & $\begin{array}{c}d_{c}\left(\mathrm{~cm}^{3} / \mathrm{mol}\right) \\
\text { from } \gamma^{\infty} \text { data }\end{array}$ & $\begin{array}{c}d_{c}\left(\mathrm{~cm}^{3} / \mathrm{mol}\right) \\
\text { from vapor } \\
\text { pressure data } \\
{[33]}\end{array}$ \\
\hline Ethyl oleate & 784.2 & 10.5 & 8.151 & \\
triacetin & 742.8 & 31.1 & 5.969 & 5.617 \\
tripalmitin & 1020.3 & 5.1 & 11.439 & 11.649 \\
tristearin & 1042.3 & 4.5 & 11.986 & 12.677 \\
triolein & 1043.3 & 4.5 & 11.839 & \\
trilinolein & 1044.3 & 4.9 & & 11.640 \\
monopalmitin & 850.7 & 12.7 & 7.935 & 8.077 \\
monoolein & 874.2 & 11.9 & $8.309^{\mathrm{c}}$ & \\
dipalmitin & 942.7 & 8.1 & 9.539 & \\
diolein & 989.8 & 8.8 & $10.493^{\mathrm{c}}$ & \\
\hline
\end{tabular}

${ }^{\mathrm{a}}$ Fedors group contribution approach [22].

${ }^{b}$ From (A.5) of the appendix.

${ }^{\mathrm{c}}$ From solubility data in $\mathrm{SCCO}_{2}[10,12]$.

All pure group and binary group interactions parameters employed in the phase equilibria simulations are given in Table 6. As mentioned previously, the alcohol-ester and alcohol-TG parameters were regressed in this work, while the rest of parameters were obtained from the literature [19].

The feed material of the countercurrent SFE experiments (i.e., the product of the ethanolysis of sunflower oil) was represented using appropriate model substances. Since the analysis of the fatty acid profile of this mixture provided 
TABLE 5: Supercritical $\mathrm{CO}_{2}$ fractionation of a glyceride mixture: comparison between the experimental and calculated compositions of MGs, DGs, and TGs in the residue.

\begin{tabular}{|c|c|c|c|c|c|c|c|c|c|}
\hline \multirow{3}{*}{ Ext. } & \multirow{3}{*}{$\mathrm{S} / \mathrm{F}$} & \multirow{3}{*}{$T(\mathrm{~K})$} & \multirow{3}{*}{$P(\mathrm{MPa})$} & \multicolumn{6}{|c|}{ Composition of residue, \% weight (fatty acid ethyl esters and $\mathrm{CO}_{2}$-free basis) } \\
\hline & & & & \multicolumn{3}{|c|}{ Experimental } & \multicolumn{3}{|c|}{ GC-EoS prediction } \\
\hline & & & & MGs & DGs & TGs & MGs & DGs & TGs \\
\hline 1 & 15 & 333 & 18 & 28.4 & 55.4 & 16.1 & 30.2 & 53.1 & 16.7 \\
\hline 2 & 15 & 333 & 20 & 25.2 & 56.1 & 18.7 & 27.9 & 54.3 & 17.9 \\
\hline 3 & 15 & 333 & 22 & 23.9 & 56.7 & 19.4 & 24.8 & 55.4 & 19.8 \\
\hline 4 & 15 & 313 & 16 & 23.5 & 53.5 & 23.0 & 26.3 & 54.3 & 19.4 \\
\hline 5 & 20 & 313 & 18 & 23.0 & 57.1 & 20.0 & 18.2 & 57.0 & 24.8 \\
\hline 6 & 20 & 333 & 25 & 21.2 & 57.8 & 21.0 & 12.8 & 58.8 & 28.4 \\
\hline 7 & 20 & 353 & 25 & 18.8 & 59.3 & 21.9 & 24.4 & 56.5 & 19.1 \\
\hline 8 & 20 & 368 & 25 & 21.5 & 57.3 & 21.2 & 28.4 & 54.6 & 17.0 \\
\hline
\end{tabular}

TABLE 6: GC-EoS pure group and binary interaction parameters used in this work.

(a) Pure group parameters

\begin{tabular}{lccccc}
\hline & Reference temperature & Group surface area & \multicolumn{3}{c}{ Pure group energy parameters } \\
& $T^{*}$ & $q$ & $g$ & $g^{\prime}$ & -0.9274 \\
\hline $\mathrm{CH}_{3}$ & 600 & 0.848 & 316910 & -0.8755 & 0.0 \\
$\mathrm{CH}_{2}$ & 600 & 0.540 & 356080 & -0.7631 & 0.0 \\
$\mathrm{CH}=\mathrm{CH}$ & 600 & 0.867 & 403590 & -1.0930 & 0.0 \\
$\mathrm{CH}_{2} \mathrm{COO}$ & 600 & 1.420 & 831400 & -1.0930 & 0.0 \\
$\mathrm{CH}_{3} \mathrm{COO}$ & 600 & 1.728 & 346350 & -1.3460 & 0.0 \\
$\mathrm{TG}^{a}$ (triglyceride) & 600 & 3.948 & 1207500 & -0.6444 & 0.0 \\
$\mathrm{CH}_{2} \mathrm{OH}$ & 512.6 & 1.124 & 1207500 & -0.6444 & 0.0 \\
$\mathrm{CHOH}$ & 512.6 & 0.908 & 531890 & -0.5780 & 0.0 \\
$\mathrm{CO}_{2}$ & 304.2 & 1.261 & & & 0 \\
\hline
\end{tabular}

(b) Binary group interaction parameters

\begin{tabular}{|c|c|c|c|c|c|}
\hline \multirow{2}{*}{$i$} & \multirow{2}{*}{$j$} & \multicolumn{2}{|c|}{ Attractive energy parameters } & \multicolumn{2}{|c|}{ Nonrandomness parameters } \\
\hline & & $k_{i j}$ & $k_{i j}^{\prime}$ & $\alpha_{i j}$ & $\alpha_{j i}$ \\
\hline \multirow{6}{*}{$\mathrm{CO}_{2}$} & $\mathrm{CH}_{3}$ & 0.898 & 0.0 & 4.683 & 4.683 \\
\hline & $\mathrm{CH}_{2}$ & 0.874 & 0.0 & 4.683 & 4.683 \\
\hline & $\mathrm{CH}=\mathrm{CH}$ & 0.948 & 0.0 & 0.0 & 0.0 \\
\hline & $\mathrm{CH}_{2} \mathrm{COO}$ & 1.115 & 0.094 & -1.615 & -1.615 \\
\hline & TG & 1.094 & 0.112 & -1.651 & -1.651 \\
\hline & $\mathrm{CH}_{2} \mathrm{OH} / \mathrm{CHOH}$ & 0.985 & 0.0 & 0.468 & -0.390 \\
\hline \multirow{4}{*}{ TG } & $\mathrm{CH}_{3} / \mathrm{CH}_{2}$ & 0.860 & 0.0 & 0.0 & 0.0 \\
\hline & $\mathrm{CH}=\mathrm{CH}$ & 0.883 & 0.0 & 0.0 & 0.0 \\
\hline & $\mathrm{CH}_{2} \mathrm{COO} / \mathrm{CH}_{3} \mathrm{COO}$ & 1.237 & 0.0 & -8.700 & -3.656 \\
\hline & $\mathrm{CHOH} / \mathrm{CH}_{2} \mathrm{OH}^{\mathrm{b}}$ & 1.079 & -0.029 & -10.53 & -11.23 \\
\hline \multirow{3}{*}{$\mathrm{CH}_{2} \mathrm{COO} / \mathrm{CH}_{3} \mathrm{COO}$} & $\mathrm{CH}_{3} / \mathrm{CH}_{2}$ & 0.869 & 0.0 & 0.0 & 0.0 \\
\hline & $\mathrm{CH}=\mathrm{CH}$ & 1.006 & 0.0 & -0.876 & -0.876 \\
\hline & $\mathrm{CHOH} / \mathrm{CH}_{2} \mathrm{OH}^{\mathrm{b}}$ & 0.996 & -0.163 & 0.654 & -2.612 \\
\hline \multirow{3}{*}{$\mathrm{CH}_{2} \mathrm{OH} / \mathrm{CHOH}$} & $\mathrm{CH}_{3}$ & 0.715 & 0.0 & 10.220 & 1.471 \\
\hline & $\mathrm{CH}_{2}$ & 0.682 & 0.0 & 10.220 & 1.471 \\
\hline & $\mathrm{CH}=\mathrm{CH}$ & 0.816 & 0.0 & 3.862 & 2.447 \\
\hline
\end{tabular}

$\mathrm{a}\left(\mathrm{CH}_{3} \mathrm{COO}\right)_{2} \mathrm{CH}_{2} \mathrm{COO}$.

bParameters regressed in this work. 
oleic acid content higher than $80 \%$, the feed raw material was represented as $48.2 \%$ ethyl oleate, $17.0 \%$ monoolein, $26.5 \%$ diolein, and $7.9 \%$ triolein (weight basis).

Using the selected representative substance (pure component parameters are given in Table 4 ) and the parameter matrix given in Table 6, the residue composition was calculated in a completely predictive manner using the GC-EoS model. The SFE process was mathematically solved within a sequential process simulator (FORTRAN language) that includes rigorous models for a high-pressure multistage extractor [34] and a multiphase flash [35].

Table 5 gives the residue composition obtained in the different experimental assays, as predicted by the GC-EoS model. These results are also given on an FAEE-free basis since the weight fraction of FAEE in the residues calculated using the GC-EoS model was lower than 0.02 in all cases. That is, following the experimental observations, the GCEoS predicted almost a complete removal of FAEE from the feed mixture in all simulated conditions. Furthermore, the GC-EoS prediction of residue composition is very satisfactory, being the standard deviations, respectively, 8.17, 1.14, and 6.49 for MGs, DGs, and TGs weight fractions.

Further inspection of experiments 1 to 3 in Table 5 shows that the increase of pressure at $333 \mathrm{~K}$ results in a reduction of MGs concentration and an increase of TGs concentration; the same tendency is predicted by the GC-EoS model.

As mentioned before, differences in vapor pressure between MGs, DGs, and TGs could have great influence on the process selectivity, thus the effect of high extraction temperatures was experimentally studied (extractions 6 to 8 in Table 5). The experimental results show no significant effect of temperature on the residue composition. On the contrary, model predictions clearly show that, with increasing temperature, MGs concentration increases while DGs and TGs concentrations decrease. This discrepancy could be attributed to an overestimation of the increase of MGs vapor pressure with temperature in comparison with DGs and TGs vapor pressures, as predicted by the GC-EoS model.

\section{Conclusions}

The alcohol-ester and alcohol-triglyceride GC-EoS group interaction parameters were regressed in this work using a large set of VLE data of binary 1-alcohol + ester mixtures, and $\gamma^{\infty}$ data of 1-alcohols and 2-alcohols in triglycerides.

The validity of the parameters regressed was tested using the GC-EoS model to predict the fractionation of a complex glyceride mixture, obtained from the lipase-catalyzed ethanolysis of sunflower oil. Countercurrent SFE assays were carried out in this work using a $100 \mathrm{~cm}$ packed column, at pressures ranging from 16 to $25 \mathrm{MPa}$ and temperatures from 313 to $368 \mathrm{~K}$.

The simulation of the extraction processes was supported by an appropriate selection of model substances to represent the product of the ethanolysis reaction (feed raw material of the countercurrent SFE experiments). Satisfactory agreement between experimental and simulated data was in general observed. Main discrepancies between experimental and predicted results were observed at high extraction temper- atures $(353-368 \mathrm{~K})$, that is when the model is extrapolated to a temperature range not employed in the regression of parameters.

\section{Appendix}

The residual Helmholtz energy in the GC-EoS model is described by two terms: a repulsive, or free volume term, and a contribution from attractive intermolecular forces:

$$
A^{r}=A_{\mathrm{fv}}^{r}+A_{\mathrm{att}}^{r} .
$$

The free volume contribution is modeled assuming hard sphere behavior for the molecules, characterizing each substance $i$ by a temperature-dependent hard sphere diameter $d_{i}$. A Carnahan-Starling type of hard sphere expression for mixtures is adopted:

$$
\frac{A_{\mathrm{fv}}^{r}}{\mathrm{RT}}=3\left(\frac{\lambda_{1} \lambda_{2}}{\lambda_{3}}\right)(Y-1)+\left(\frac{\lambda_{2}^{3}}{\lambda_{3}^{2}}\right)\left(-Y+Y^{2}-\ln Y\right)+n \ln Y,
$$

where

$$
Y=\left(1-\frac{\pi \lambda_{3}}{6 V}\right)^{-1}, \quad \lambda_{k}=\sum_{i}^{\mathrm{NC}} n_{i} d_{i}^{K},
$$

$\mathrm{NC}$ is the number of components, $n_{i}$ is the number of moles of component $i$, and $V$ is the total volume. The following temperature-dependent generalized expression is assumed for $d_{i}$

$$
d_{i}=1.065655 d_{c i}\left\{1-0.12 \exp \left[\frac{-2 T_{c i}}{(3 T)}\right]\right\},
$$

where $d_{c i}$ is the pure component critical hard sphere diameter (a parameter related with molecular size), which is calculated as

$$
d_{c i}=\left(\frac{0.08943 R T_{c i}}{P_{c i}}\right)^{1 / 3}
$$

when the compound coincides with a group (e.g., $\mathrm{H}_{2} \mathrm{O}, \mathrm{CO}_{2}$, $\mathrm{H}_{2}$, etc.). For the remaining cases, $d_{c i}$ is fitted to a point of the pure component vapor pressure curve, usually the normal boiling point.

For the evaluation of the attractive contribution to the Helmholtz energy, a group contribution version of a densitydependent NRTL-type expression is derived:

$$
\frac{A_{\mathrm{att}}^{r}}{\mathrm{RT}}=-\frac{z}{2} \sum_{i}^{\mathrm{NC}} n_{i} \sum_{j}^{\mathrm{NG}} v_{j}^{i} q_{j} \sum_{k}^{\mathrm{NG}} \frac{\theta_{k} g_{k j} \tilde{q} \tau_{k j} / \mathrm{RTV}}{\sum_{l}^{\mathrm{NG}} \theta_{l} \tau_{l j}},
$$

where

$$
\begin{gathered}
\theta_{j}=\left(\frac{q_{j}}{\tilde{q}}\right) \sum_{i}^{\mathrm{NC}} n_{i} v_{j}^{i}, \quad \tilde{q}=\sum_{i}^{\mathrm{NC}} n_{i} \sum_{j}^{\mathrm{NG}} v_{j}^{i} q_{j}, \\
\tau_{i j}=\exp \left[\frac{\alpha_{i j} \Delta g_{i j} \tilde{q}}{(\mathrm{RTV} V)}\right], \\
\Delta g_{i j}=g_{i j}-g_{j j},
\end{gathered}
$$


NG is the number of groups, $z$ is the number of nearest neighbors to any segment (set to 10$), v_{j}^{i}$ the number of groups type $j$ in molecule $i, q_{j}$ the number of surface segments assigned to group $j, \theta_{k}$ the surface fraction of group $k, \tilde{q}$ the total number of surface segments, $g_{i j}$ the attraction energy parameter for interactions between groups $i$ and $j$, and $\alpha_{i j}$ the NRTL nonrandomness parameter $\left(\alpha_{i j} \neq \alpha_{j i}\right)$. The interactions between unlike groups are calculated from:

$$
g_{i j}=k_{i j}\left(g_{i i} g_{j j}\right)^{1 / 2}, \quad\left(k_{i j}=k_{j i}\right)
$$

with the following temperature dependences for the interaction parameters:

$$
\begin{gathered}
\mathrm{g}_{j j}=g_{j j}^{*}\left(1+g_{j j}^{\prime}\left(\frac{T}{T_{j}^{*}}-1\right)+g_{j j}^{\prime \prime} \ln \left(\frac{T}{T_{j}^{*}}\right)\right), \\
k_{i j}=k_{i j}^{*}\left\{1+k_{i j}^{\prime} \ln \left[\frac{2 T}{\left(T_{i}^{*}+T_{j}^{*}\right)}\right]\right\},
\end{gathered}
$$

where $g_{j j}^{*}$ is the interaction parameter for reference temperature $T_{j}^{*}$.

\section{Acknowledgments}

This work has been financed by project ALIBIRD (S2009AGR-1469) from the Comunidad Autónoma de Madrid and project FUN-C-FOOD (CSD2007-00063, CONSOLIDERINGENIO 2010).

\section{References}

[1] L. L. M. Van Deenen and G. H. De Haas, "The substrate specificity of phospholipase A," Biochimica et Biophysica Acta, vol. 70, no. C, pp. 538-553, 1963.

[2] F. U. Ahmed, "Efficient synthesis of fatty monoglyceride sulfates from fatty acids and fatty acid methyl esters," Journal of the American Oil Chemists' Society, vol. 67, no. 1, pp. 8-14, 1990.

[3] F. Hamam and S. M. Budge, "Structured and specialty lipids in continuous packed column reactors: comparison of production using one and two enzyme beds," Journal of the American Oil Chemists' Society, vol. 87, no. 4, pp. 385-394, 2010.

[4] H. Birnbaum, "The monoglycerides: manufacture, concentration, derivatives and applications," Bakers Digest, vol. 55, pp. 6-16, 1981.

[5] Y. Katsuragi, T. Yasukawa, N. Matsuo, B. D. Flickinger, I. Tokimitsu, and M. G. Matlock, Diacylglycerol Oil, AOCS Press, 2004.

[6] F. Sahena, I. S. M. Zaidul, S. Jinap et al., "Application of supercritical CO2 in lipid extraction-a review," Journal of Food Engineering, vol. 95, no. 2, pp. 240-253, 2009.

[7] J. W. King, E. Sahle-Demessie, F. Temelli, and J. A. Teel, "Thermal gradient fractionation of glyceride mixtures under supercritical fluid conditions," Journal of Supercritical Fluids, vol. 10, no. 2, pp. 127-137, 1997.

[8] Ö. Güçlü-Üstündağ and F. Temelli, "Correlating the solubility behavior of fatty acids, mono-, di-, and triglycerides, and fatty acid esters in supercritical carbon dioxide," Industrial and Engineering Chemistry Research, vol. 39, no. 12, pp. 4756-4766, 2000 .
[9] Ö. Güçlü-Üstündag and F. Temelli, “Correlating the solubility behavior of minor lipid components in supercritical carbon dioxide," Journal of Supercritical Fluids, vol. 31, no. 3, pp. 235253, 2004.

[10] I. Ashour and H. Hammam, "Equilibrium solubility of pure mono-, di-, and trilaurin in supercritical carbon dioxide experimental measurements and model prediction," The Journal of Supercritical Fluids, vol. 6, no. 1, pp. 3-8, 1993.

[11] H. Hammam, "Solubilities of pure lipids in supercritical carbon dioxide," The Journal of Supercritical Fluids, vol. 5, no. 2, pp. 101-106, 1992.

[12] W. B. Nilsson, E. J. Gauglitz, and J. K. Hudson, "Solubilities of methyl oleate, oleic acid, oleyl glycerols, and oleyl glycerol mixtures in supercritical carbon dioxide," Journal of the American Oil Chemists Society, vol. 68, no. 2, pp. 87-91, 1991.

[13] S. Skjold-Jørgensen, "Group contribution equation of state (GC-EOS): a predictive method for phase equilibrium computations over wide ranges of temperature and pressures up to 30 MPa," Industrial and Engineering Chemistry Research, vol. 27, no. 1, pp. 110-118, 1988.

[14] S. Skjold-Jørgensen, "Gas solubility calculations. II. Application of a new group-contribution equation of state," Fluid Phase Equilibria, vol. 16, no. 3, pp. 317-351, 1984.

[15] S. Espinosa, S. Diaz, and E. A. Brignole, "Thermodynamic modeling and process optimization of supercritical fluid fractionation of fish oil fatty acid ethyl esters," Industrial and Engineering Chemistry Research, vol. 41, no. 6, pp. 1516-1527, 2002.

[16] L. Vázquez, C. F. Torres, T. Fornari, F. J. Señoráns, and G. Reglero, "Recovery of squalene from vegetable oil sources using countercurrent supercritical carbon dioxide extraction," Journal of Supercritical Fluids, vol. 40, no. 1, pp. 59-66, 2007.

[17] L. Vázquez, A. M. Hurtado-Benavides, G. Reglero, T. Fornari, E. Ibáñez, and F. J. Señoráns, "Deacidification of olive oil by countercurrent supercritical carbon dioxide extraction: experimental and thermodynamic modeling," Journal of Food Engineering, vol. 90, no. 4, pp. 463-470, 2009.

[18] T. Fornari, C. F. Torres, F. J. Señoráns, and G. Reglero, "Simulation and optimization of supercritical fluid purification of phytosterol esters," AIChE Journal, vol. 55, no. 4, pp. 10231028, 2009.

[19] T. Fornari, "Revision and summary of the group contribution equation of state parameter table: application to edible oil constituents," Fluid Phase Equilibria, vol. 262, no. 1-2, pp. 187-209, 2007.

[20] C. F. Torres, T. Fornari, D. Tenllado, F. J. Señoráns, and G. Reglero, "A predictive kinetic study of lipase-catalyzed ethanolysis reactions for the optimal reutilization of the biocatalyst," Biochemical Engineering Journal, vol. 42, no. 2, pp. 105-110, 2008.

[21] C. F. Torres, L. Vázquez, F. J. Señoráns, and G. Reglero, "Study of the analysis of alkoxyglycerols and other non-polar lipids by liquid chromatography coupled with evaporative light scattering detector," Journal of Chromatography A, vol. 1078, no. 1-2, pp. 28-34, 2005.

[22] R. F. Fedors, "A relationship between chemical structure and the critical temperature," Chemical Engineering Communications, vol. 16, pp. 149-151, 1982.

[23] S. B. Bottini, T. Fornari, and E. A. Brignole, "Phase equilibrium modelling of triglycerides with near critical solvents," Fluid Phase Equilibria, vol. 158-160, pp. 211-218, 1999.

[24] J. Fernandez, C. Berro, and M. I. Paz Andrade, "Excess thermodynamics functions of 1-propanol + methyl propanoate and 1-propanol + methyl butanoate systems," Fluid Phase Equilibria, vol. 20, pp. 145-153, 1985. 
[25] J. Fernández, C. Berro, and A. Péneloux, "Excess Gibbs energies and excess volumes of some alcohol-methyl ester binary mixtures," Journal of Chemical and Engineering Data, vol. 32, no. 1, pp. 17-22, 1987.

[26] P. Susial, J. Ortega, C. De Alfonso, and C. Alonso, "Vaporliquid equilibrium measurements for methyl propanoateethanol and methyl propanoate-propan-1-ol at $101.32 \mathrm{kPa}$," Journal of Chemical and Engineering Data, vol. 34, no. 2, pp. 247-250, 1989.

[27] J. Gmehling, U. Onken, and W. Arlt, Vapour-Liquid Equilibrium Data Collection, DECHEMAM, Frankfurt, Germany, 1979.

[28] J. Ortega, P. Susial, and C. De Alfonso, "Vapor-liquid equilibrium measurements at $101.32 \mathrm{kPa}$ for binary mixtures of methyl acetate + ethanol or 1-propanol," Journal of Chemical and Engineering Data, vol. 35, no. 3, pp. 350-352, 1990.

[29] J. Ortega, J. A. Peña, and C. De Alfonso, "Isobaric vaporliquid equilibria of ethyl acetate + ethanol mixtures at $760 \pm$ $0.5 \mathrm{mmHg}$," Journal of Chemical and Engineering Data, vol. 31, no. 3, pp. 339-342, 1986.

[30] C. Din, G. Foco, T. Fornari, E. A. Brignole, and S. B. Bottini, "Infinite dilution activity coefficients in triglycerides," Latin American Applied Research, vol. 25, pp. 243-247, 1995.

[31] G. Foco, A. Bermudez, and S. Bottini, "Infinite dilution activity coefficients in mono-, di-, and tripalmitin and palmitic acid," Journal of Chemical and Engineering Data, vol. 41, no. 5, pp. 1071-1074, 1996.

[32] G. M. Foco, A. M. Bermúdez, and S. B. Bottini, "Characterization of high molecular weight compounds by infinite dilution activity coefficients," in Proceedings of the (EQUIFASE '99), J. Tojo and A. Arce, Eds., pp. 268-273, Vigo, Spain, June 1999.

[33] E. S. Perry, W. H. Weber, and B. F. Daubert, "Vapor pressures of phlegmatic liquids. I. Simple and mixed triglycerides," Journal of the American Chemical Society, vol. 71, no. 11, pp. 3720-3726, 1949.

[34] E. A. Brignole, P. M. Andersen, and A. Fredenslund, "Supercritical fluid extraction of alcohols from water," Industrial and Engineering Chemistry Research, vol. 26, no. 2, pp. 254-261, 1987.

[35] M. L. Michelsen, "The isothermal flash problem. Part II. Phase-split calculation," Fluid Phase Equilibria, vol. 9, no. 1, pp. 21-40, 1982. 

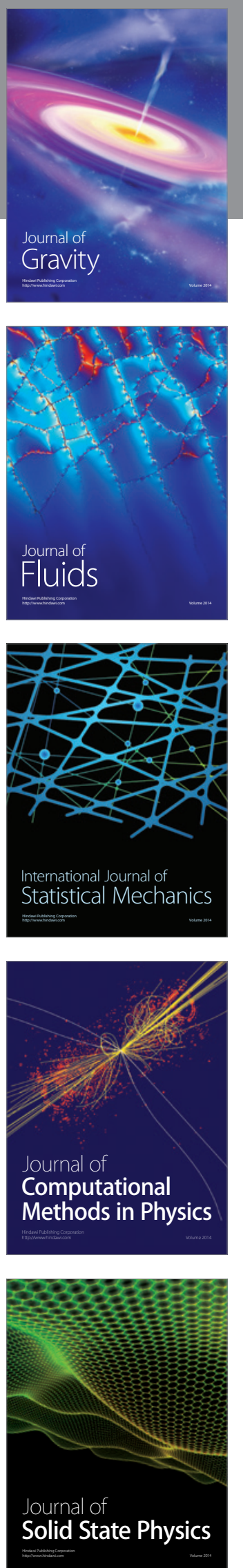

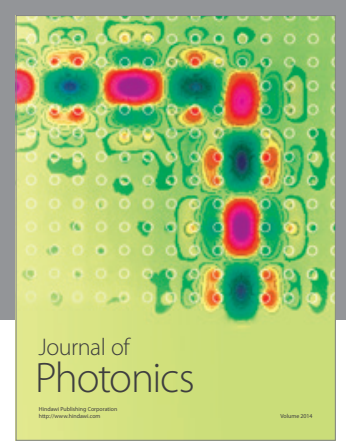

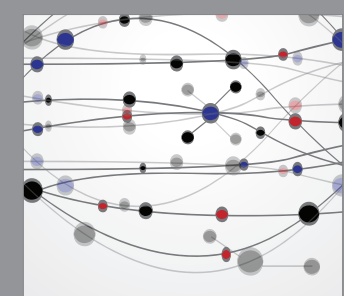

The Scientific World Journal
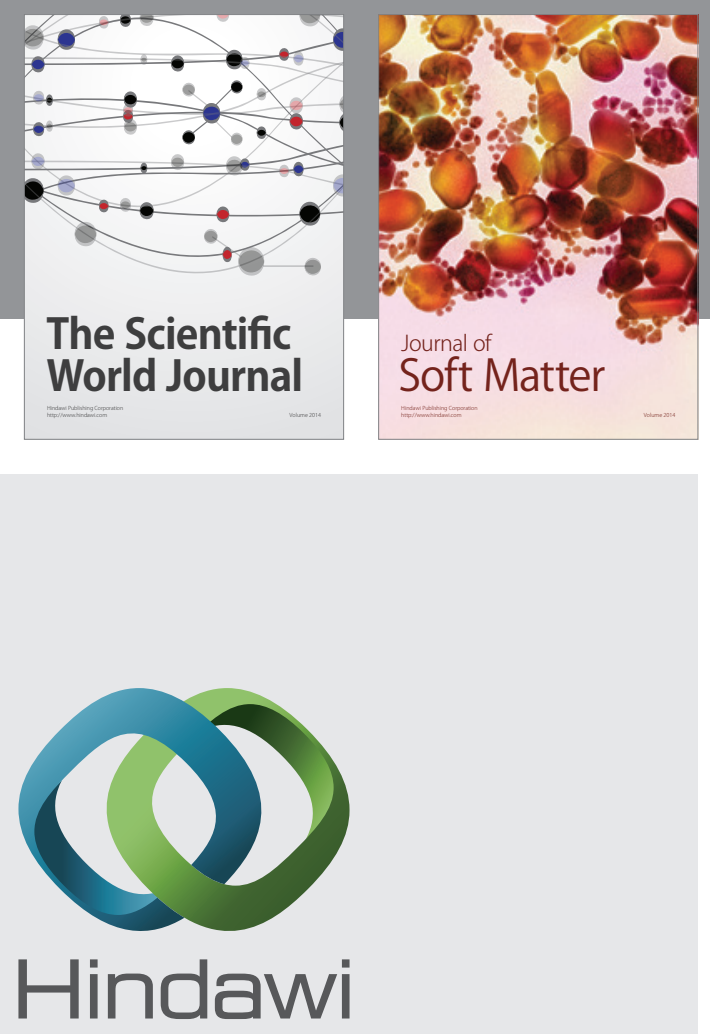

Submit your manuscripts at

http://www.hindawi.com
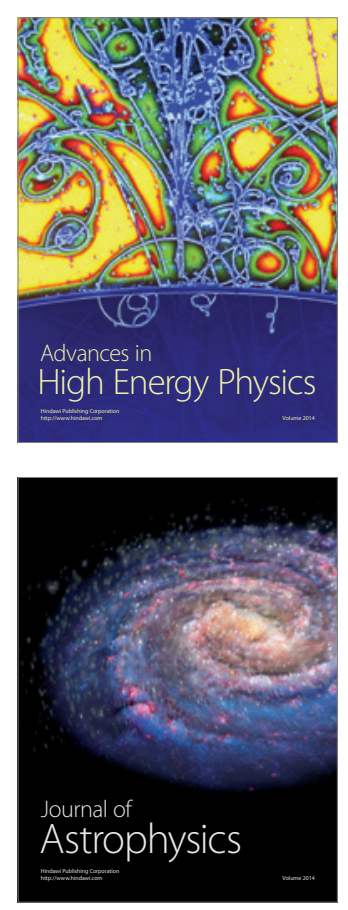
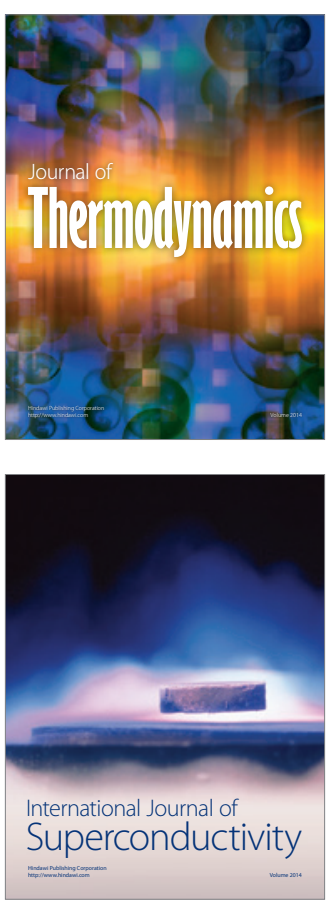
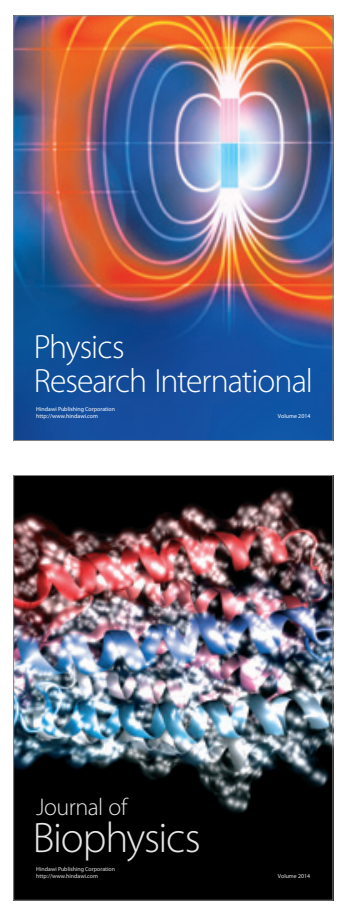
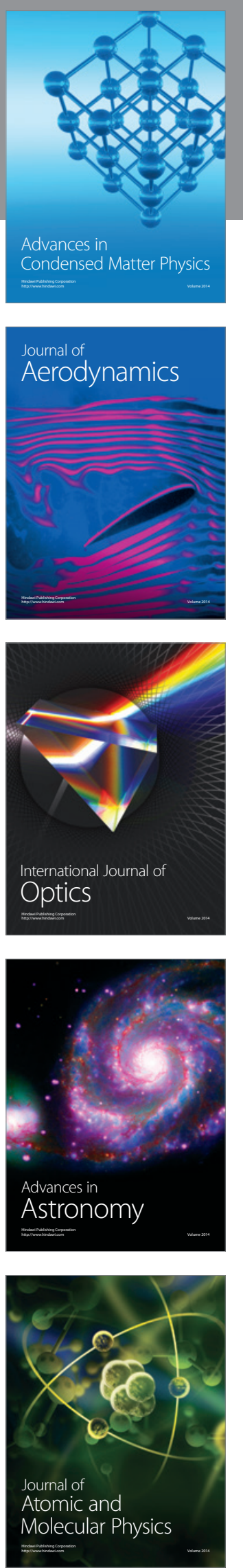